Canadian Oncology

Nursing Journal

Revue canadienne

de soins infirmiers

en oncologie

Volume 31, Issue 3 • Summer 2021

elSSN: 2368-8076 


\title{
The relationships of unmet needs with quality of life and characteristics of Indonesian gynecologic cancer survivors
}

\author{
by Yati Afiyanti, Besral Besral, Haryani Haryani, Ariesta Milanti, Lina Anisa Nasution, Kemala Rita Wahidi, Dewi Gayatri
}

\begin{abstract}
Gynecologic cancer survivors' complex needs are too often overlooked. This study aimed to identify the associations between unmet needs and quality of life, and selected characteristics of Indonesian gynecologic cancer survivors. This study was a cross-sectional, correlation study. A total of 298 participants completed the Cancer Survivor Unmet Needs (CaSUN), EORTC QLQ-C30, and demographic and clinical-related questionnaires. A higher level of unmet needs was linked to lower perceived quality of life. Higher levels of unmet needs were associated with younger age, lower income, higher educational background, shorter time since diagnosis, more advanced cancer stage, and having combination therapies $(p<0.05)$. The most frequently reported unmet need of the Indonesian gynecologic cancer survivors was financial support (70.5\%). The gynecologic cancer survivors who had completed primary treatment need continuous comprehensive cancer care to help them cope with the lingering or emerging problems related to cancer and its treatment.
\end{abstract}

Key words: cancer, female, survivorship, quality of life, Indonesia

\section{INTRODUCTION}

ynecologic cancer is the cancer of the female repro$\checkmark$ ductive system, which includes cervix, uterus, ovaries, endometrium, fallopian tube, and vagina (National Cancer

\section{AUTHOR NOTES}

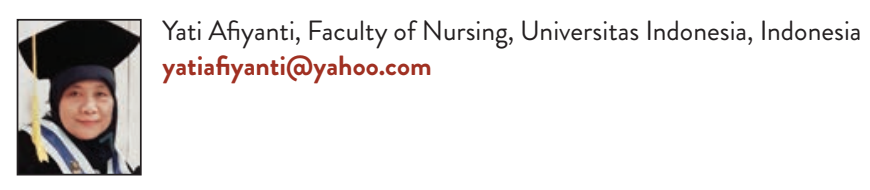

Besral Besral, Faculty of Public Health, Universitas Indonesia, Indonesia

Haryani Haryani, Faculty of medicine, public health, and nursing. School of Nursing, University Gadjah Mada, Indonesia

Ariesta Milanti, The Nethersole School of Nursing, The Chinese University of Hong Kong, Hong Kong

Lina Anisa Nasution, Faculty of Nursing, Universitas Indonesia, Indonesia

Kemala Rita Wahidi, Dharmais National Cancer Centre, Indonesia

Dewi Gayatri, Faculty of Nursing, Universitas Indonesia, Indonesia

Acknowledgement: This study was financially supported by a grant from Directorate of Higher Education, Minister of National Education, Republic of Indonesia (No: 285/UN2.R3.1/HKP.05.00/2018).

Conflict of Interest: Authors declare no conflict of interest regarding this study.
Institute, 2019). Of all female cancers, cervical cancer is the fourth most frequent cancer in women with a global estimation of 570,000 cases and 311,000 deaths in 2018 (Bray et al., 2018). Globally, the majority of cervical cancer cases occur in sub-Saharan Africa and South-eastern Asia. The lowest incidence rate is seen in Western Asia, particularly Saudi Arabia and Iraq, while some countries in Eastern Europe and Central Asia are witnessing an increasing trend of cervical cancer (Bray et al., 2018).

In Indonesia, cervical cancer is the second leading cancer among women after breast cancer (Ministry of Health Republic of Indonesia, 2019b). The estimated incidence is $23.4 / 100,000$ women with the mortality rate of $13.9 / 100,000$ women (Ministry of Health Republic of Indonesia, 2019b). Other gynecologic cancer types (i.e., uterine and ovarian cancer) were estimated to occur at a rate of 8 and 6 per 100,000 Indonesian women (Ministry of Health Republic of Indonesia, 2015).

It is well documented that improved cancer detection and treatments have contributed to the growing number of cancer survivors, including those with gynecologic malignancy (Schlumbrecht et al., 2018). Gynecologic cancer survivors are considered a special population, as they may experience some unique side effects and quality-of-life problems related to the cancer treatments, such as sexual dysfunction and pelvic insufficiency fracture (Schmeler et al., 2010; Shih et al., 2013). Yet, the complex needs of the survivors are too often overlooked (Rosenberg \& Partridge, 2017). To enhance short-term and long-term health outcomes of the cancer survivors, being aware of the individual-level challenges and unmet needs is the key to delivering a tailored intervention that works best for the survivors (Rosenberg \& Partridge, 2017).

Survivorship care has been implemented as standard cancer care in many well-resourced settings (Fitch, 2014; Nekhlyudov et al., 2017; Rosenberg \& Partridge, 2017; Salani et al., 2017). A study conducted in 10 countries in Asia Pacific region (i.e., China, Japan, Hong Kong SAR, South Korea, Myanmar, Thailand, India, Singapore, Philippines, and Australia) underlined the service gaps of survivorship care between high-income countries (HIC) and lower and middle-income countries (LMIC) (Molassiotis et al., 2017). Indonesia is in the phase of developing the survivorship care program for gynecologic cancer survivors. To inform the development of policy and practice of survivorship care for these survivors, this study explored the unmet needs, quality of life (QoL) perceptions, and associations among these variables in gynecologic cancer survivors in Indonesia. 


\section{METHODS}

A cross-sectional survey of gynecologic cancer patients was carried out in three major referral hospitals located in Jakarta Province, Yogyakarta Province, and East Java Province of Indonesia. The participant recruitment period was three months.

A convenience sample of adult patients ( $>18$ years old) with gynecologic cancer who had completed primary treatment for at least one month participated in this study. Patients were excluded in cases of having a recurrent cancer or having a cognitive disability that prevented them from taking part in the study. Nurses working at the outpatient units of the study settings assisted in recruiting the participants and collecting the data using paper-based questionnaires. A total of 310 patients were approached and 298 of them agreed to participate (response rate $=96.13 \%$ ) .

Participants completed a sociodemographic questionnaire, the Indonesian version of Cancer Survivors' Unmet Needs (CaSUN) (Hodgkinson et al., 2007a), and EORTC QLQ-C30 (Aaronson et al., 1993; Perwitasari et al., 2011). The authors made the sociodemographic questionnaire to collect the data of participants' age, marital status, level of education, employment status, and monthly family income. Furthermore, clinical data were also collected from the participants' medical record. The clinical data included the time since diagnosis, stage of the disease, metastatic cancer status, and primary treatment history.

The 35-item CaSUN divides the needs of the survivors into domains of: (1) existential survivorship, (2) comprehensive care, (3) information, (4) quality of life, and (5) relationship (Hodgkinson et al., 2007a). The items on CaSUN can be scored in terms of the domains of met, unmet, and total need, and/ or strength of need. Participants indicate whether they have no need/not applicable, a met need, or an unmet need. The unmet need is scored as weak (1), moderate (2), or strong (3). The summation of the rating of all 35 items is the total score for the CaSUN (Hodgkinson et al., 2007a). This tool has been shown to be reliable in assessing unmet needs of survivors from various cancer types in many countries (Bender et al., 2012; Molassiotis et al., 2017; Smith et al., 2013). Its Indonesian version also shows good validity and reliability (Cronbach's alpha 0.75-0.95).

EORTC QLQ-C30 measures the perceived quality of life (QoL) of cancer patients. It measures the physical, role, cognitive, emotional, and social dimensions as well as the financial impact of having cancer (Aaronson et al., 1993). EORTC QLQ-C30 has five functional scales, three symptom scales, a global health status/QoL scale, and six single items. All scales and items are rated from 0-100. A high scale score indicates a higher response level; for example, a high score for a functional scale indicates a high level of functioning (Aaronson et al., 1993). EORTC QLQ-C30 has been widely recognized as a valid and reliable tool to measure quality of life of cancer patients, including in Indonesia (Perwitasari et al., 2011).

Returned questionnaires were sorted to separate fully completed and incomplete questionnaires. Data analysis was performed on data from the fully completed questionnaires. Descriptive statistics (mean, median, SD, frequency, percentage, minimum and maximum) were used to analyze the items for the demographic and clinical characteristics, unmet needs (CASUN), and quality of life (EORTC-QLQ-C30) of the participants. The total score of the unmet needs was obtained from the summation of the 1 to 3 rating for the total 35-items of CASUN. The total score of the QoL (EORTC- QLQ-C30) was calculated from by calculating the average of the items (raw score), of which the linear transformation was applied to obtain the score 0-100 scale. Subsequently, bivariate and multivariate analyses were applied to identify the relationships between the total score of the unmet needs and QoL with the p value set at 0.05. SPSS software version 22 (SPSS Inc., Chicago, IL, USA) was used for the statistical analyses.

Ethical approvals were obtained from the Ethics Committee of the Faculty of Medicine, Universitas Gadjah Mada and Faculty of Nursing, Universitas Indonesia (Reference Number: 28/UN2.F12.D/HKP.02.04/2018). Every individual approached as a participant was informed about the basic information of the study, and those who agreed to participate were required to fulfil an informed consent prior to participation in the study.

\section{RESULTS}

A total of 298 out of 310 participants filled out the questionnaires completely. The participants' mean age was 50.3 ( $\mathrm{SD}=9.6)$. Most participants were married $(88 / 3 \%)$ and had primary and secondary educational background. Nearly half (48.7\%) were homemakers and had lower economic status with the family income less than 71 USD per month. More than one-third of the participants (37.6\%) had stage III gynecologic cancer and half had undergone chemotherapy (see Table 1).

\section{Unmet needs}

The most frequently reported unmet need of the Indonesian gynecologic cancer survivors was financial support (70.5\%). In contrast, the need for help to adapt to changes in the body was the least frequently reported unmet need - only $29.9 \%$ survivors mentioned it as an unmet need, and $43 \%$ of those reported that they did not need help on this matter. More than half participants indicated their confidence in the health are team's communication and marked this component as a met need. In terms of the total scores for each domain of unmet needs, the top three unmet needs were in the comprehensive care domain (96.6\%), the existential domain (79\%) and information domain (62\%) (see Table 2).

Analysis showed that the higher level of unmet needs (higher total scores) was linked to younger age, lower income, and higher educational background. In term of clinical profiles, the participants who were diagnosed more recently, had more advanced cancer stage, and received combination therapies also reported more unmet needs (higher total scores) than those who had been diagnosed for a longer time, with a lower cancer stage, and underwent single primary therapy (See Table 3). 


\begin{tabular}{|c|c|}
\hline Characteristics & Mean (SD) \\
\hline Age (years) & 50.3 (SD 9.6; range 20-71) \\
\hline Marital status & $f(\%)$ \\
\hline Married & $263(88.3)$ \\
\hline Single & $12(4.0)$ \\
\hline Widow & $23(7.7)$ \\
\hline \multicolumn{2}{|l|}{ Education } \\
\hline Not attending school & $20(6.7)$ \\
\hline Elementary school & $106(35.6)$ \\
\hline Junior high school & $54(18.1)$ \\
\hline Senior high school & $90(30.2)$ \\
\hline College/University & $28(9.4)$ \\
\hline \multicolumn{2}{|l|}{$\begin{array}{l}\text { Monthly family income (approx. } \\
\text { in USD) }\end{array}$} \\
\hline$<71$ & $143(48.0)$ \\
\hline $71-141$ & $75(25.2)$ \\
\hline $141-212$ & $28(9.4)$ \\
\hline $212-282$ & $23(7.7)$ \\
\hline $282-353$ & $8(2.7)$ \\
\hline$>353$ & $21(7.0)$ \\
\hline \multicolumn{2}{|l|}{ Employment } \\
\hline Homemaker & $145(48.7)$ \\
\hline Government official & $11(3.7)$ \\
\hline Private employee & $27(9.1)$ \\
\hline Self-employed & $59(19.8)$ \\
\hline Factory worker & $44(14.8)$ \\
\hline Retired & $12(4.0)$ \\
\hline \multicolumn{2}{|l|}{ Stage of Cancer } \\
\hline 1 & $54(18.1)$ \\
\hline II & $86(28.9)$ \\
\hline III & $112(37.6)$ \\
\hline IV & $13(4.4)$ \\
\hline Unknown & $33(11.1)$ \\
\hline \multicolumn{2}{|l|}{ Time from diagnosis } \\
\hline$<1$ year & $110(36.9)$ \\
\hline$\geq 1$ year, $<2$ years & $124(41.6)$ \\
\hline$\geq 2$ years, $<4$ years & $35(11.7)$ \\
\hline$\geq 4$ years & $29(9.8)$ \\
\hline \multicolumn{2}{|l|}{ Metastatic cancer } \\
\hline Yes & $57(19.2)$ \\
\hline No & $241(80.9)$ \\
\hline \multicolumn{2}{|l|}{ Primary treatment history } \\
\hline Chemotherapy & $149(50)$ \\
\hline Chemotherapy \& radiation & $49(16.4)$ \\
\hline Radiation & $38(12.8)$ \\
\hline Surgery & $26(8.7)$ \\
\hline Other & $36(12.1)$ \\
\hline
\end{tabular}

\section{Quality of life}

The quality of life (QoL) total score is negatively correlated with the unmet need total score $(\mathrm{p}=0.000)$ (see Table 4). Meanwhile, all six symptom variables (i.e., fatigue, nausea/ vomiting, pain, poor appetite, constipation, and financial problems) have positive correlations with the unmet needs $(\mathrm{p}<0.05)$. This implies that the gynecological cancer survivors with lower perceived QoL and higher symptom experience had more unmet needs. Moreover, 10 out of 15 quality-of-life (QoL) domains were significantly related to the unmet needs; and four variables (global health status, physical functioning, emotional functioning, and cognitive functioning) had negative correlations with the unmet needs. Participants with a better global health status and physical, emotional, and cognitive functions reported fewer unmet needs. In addition, the top three most reported symptoms were insomnia (43.2\%), financial problems (38.8\%), and pain (36.8\%).

\section{DISCUSSION}

Our main result indicated that the higher level of unmet needs was linked to lower perceived QoL. This is consistent with findings of previous studies in gynecologic cancer patients who were undergoing active treatment in Indonesia (Putri et al., 2017) and the post-treatment gynecologic cancer survivors in Australia (Hodgkinson et al., 2007b; Urbaniec et al., 2011). Similar findings were also found in studies on survivors of mixed cancer types (Molassiotis et al., 2017; So et al., 2013) and breast cancer (So et al., 2014).

Our findings provide evidence that the unmet needs of the survivors have a negative effect on their quality of life. This condition may be attributed to the minimum survivorship care that the Indonesian survivors receive. Cancer survivors normally will have follow-up visits to the outpatient department in a certain time span to check their health condition and complete surveillance for recurrence. However, the continuity of care by the nurses is still very poor.

The survivors in this study, however, mostly did not report unmet needs in psychosocial care or the informational domain as was reported in previous studies in Western countries and in Hong Kong (Armes et al., 2009; Knobf et al., 2012; So et al., 2013). They may not realize that there actually is survivorship care for cancer survivors, so they did not demand anything related to care. They reported their unmet needs about the monetary issue instead.

The financial issue emerged as the most paramount burden for Indonesian gynecological cancer survivors in this study. Apart from being reported as the largest unmet need, the financial problem was the second most prominent symptom experience for the survivors after insomnia. Over seventy per cent of our participants lived on the monthly family income of less than 141 USD. This amount is even lower than the standard living cost for one person, as estimated in the minimum regional wage (varied in each region where the study was conducted, Jakarta $=\sim 281$ USD, Surabaya $=\sim 276$ USD, Yogyakarta $=\sim 112$ USD). However, we did not identify 


\begin{tabular}{|c|c|c|c|}
\hline Survivor's Needs - individual items & No need & Met need & Unmet need \\
\hline \multicolumn{4}{|l|}{ Existential survivorship (14 items) } \\
\hline 10 Reducing stress & 29.9 & 29.9 & 40.3 \\
\hline 19 Concerns about cancer recurrence & 16.4 & 27.5 & 56.0 \\
\hline 20 Emotional support & 8.1 & 56.0 & 35.9 \\
\hline 23 Renewing relationships with spouse & 36.9 & 22.5 & 40.6 \\
\hline 24 Talking to other cancer patients & 45.3 & 17.8 & 36.9 \\
\hline 25 Explaining cancer to others & 12.8 & 46.3 & 40.9 \\
\hline 26 Adapting to changes in my body & 43.0 & 27.2 & 29.9 \\
\hline 29 Moving on with my life & 7.0 & 49.0 & 44.0 \\
\hline 30 Strengthening my beliefs & 10.1 & 53.0 & 36.9 \\
\hline 31 Acknowledging the impact & 39.9 & 23.2 & 36.9 \\
\hline 32 Expectations as a survivor & 16.4 & 44.0 & 39.6 \\
\hline 33 Decisions about my future & 12.8 & 51.7 & 35.6 \\
\hline 34 Improving spiritual beliefs & 6.7 & 54.0 & 39.3 \\
\hline 35 Making my life count & 6.7 & 49.3 & 44.0 \\
\hline \multicolumn{4}{|l|}{ Comprehensive care } \\
\hline 4 Best medical care & 1.7 & 57.0 & 41.3 \\
\hline 5 Local health care service & 11.7 & 35.6 & 52.7 \\
\hline 6 Involved with health care team & 4.7 & 59.7 & 35.6 \\
\hline 7 Knowing that health care team work together & 2.7 & 62.8 & 34.6 \\
\hline 8 Having complaints addressed & 2.3 & 55.0 & 42.6 \\
\hline 18 Accessible hospital parking & 31.9 & 31.5 & 36.6 \\
\hline \multicolumn{4}{|l|}{ Information (3 items) } \\
\hline 1 Up-to-date information & 2.7 & 45.3 & 52.0 \\
\hline 2 Information for family members & 4.0 & 54.4 & 41.6 \\
\hline 3 Easy to understand information & 1.3 & 54.7 & 44.0 \\
\hline \multicolumn{4}{|l|}{ Quality of Life } \\
\hline 11 Managing side effects & 13.4 & 38.3 & 48.3 \\
\hline 12 Changes in quality of life & 18.1 & 41.3 & 40.6 \\
\hline \multicolumn{4}{|l|}{ Relationships (3 items) } \\
\hline 21 Support partner/family & 19.5 & 45.3 & 35.2 \\
\hline 22 Managing cancer impact on my relationship & 36.9 & 22.5 & 40.6 \\
\hline 27 Sexual problems & 52.0 & 10.4 & 37.6 \\
\hline \multicolumn{4}{|l|}{ Other } \\
\hline 9 Information about complementary therapy & 54.0 & 10.7 & 35.2 \\
\hline 15 Financial support and/or government benefit & 13.1 & 16.4 & 70.5 \\
\hline 17 Help to access legal services & 21.8 & 12.4 & 65.8 \\
\hline 14 Help to maintain employment & 33.6 & 30.2 & 36.2 \\
\hline
\end{tabular}




\begin{tabular}{|c|c|c|c|c|}
\hline \multirow[t]{2}{*}{ Variable } & \multicolumn{2}{|c|}{ Full Model } & \multicolumn{2}{|c|}{ Final Model } \\
\hline & B & Sig. & B & Sig. \\
\hline Constant & 22.3 & 0.000 & 23.3 & 0.000 \\
\hline Age (year) & -0.2 & 0.010 & -0.2 & 0.006 \\
\hline Income (Rupiah) & -1.4 & 0.003 & -1.5 & 0.002 \\
\hline $\begin{array}{l}\text { Time since } \\
\text { diagnosis (year) }\end{array}$ & -1.6 & 0.007 & -1.6 & 0.005 \\
\hline \multicolumn{5}{|l|}{$\begin{array}{l}\text { Education Elementary } \\
\text { school (ref.) }\end{array}$} \\
\hline Junior high school & 3.1 & 0.065 & 3.0 & 0.066 \\
\hline Senior high school & 2.5 & 0.123 & 2.4 & 0.127 \\
\hline College/University & 4.6 & 0.068 & 4.1 & 0.091 \\
\hline \multicolumn{5}{|l|}{ Cancer stage I (ref.) } \\
\hline II & 3.2 & 0.069 & 3.1 & 0.079 \\
\hline III & 7.2 & 0.000 & 7.0 & 0.000 \\
\hline IV & 3.2 & 0.127 & 2.8 & 0.158 \\
\hline \multicolumn{5}{|l|}{$\begin{array}{l}\text { Primary treatment } \\
\text { history Radiotherapy } \\
\text { (ref.) }\end{array}$} \\
\hline Chemoradiation & 2.9 & 0.040 & 3.1 & 0.028 \\
\hline Surgery & -2.5 & 0.112 & -2.4 & 0.121 \\
\hline Metastases & -1.3 & 0.421 & & NS \\
\hline Marital status & -0.4 & 0.836 & & NS \\
\hline \multicolumn{5}{|l|}{$\begin{array}{l}\text { Occupation Civil } \\
\text { servant (ref.) }\end{array}$} \\
\hline $\begin{array}{l}\text { Employee of } \\
\text { private company }\end{array}$ & 1.1 & 0.532 & & NS \\
\hline Housewife & 0.9 & 0.551 & & NS \\
\hline
\end{tabular}

if the family income changed from before the cancer diagnosis and treatment, as the women might have had limitations to productivity since having cancer.

This finding reflects financial toxicity, that is, the financial hardship and the subjective financial distress due to cancer and its treatment cost (Ratain, 2009; Yabroff et al., 2004). There is a growing concern about financial toxicity as a serious burden for the cancer survivors, especially in the United States where the treatment costs, including the out of pocket (OOP) costs, are increasing (Altice et al., 2017; Hastert et al., 2018; Yabroff
Table 4. The relationships of the quality of life and unmet needs $(n=298)$

\begin{tabular}{|c|c|c|}
\hline Variable & Analyses & \\
\hline & Mean (SD) & $\begin{array}{l}\text { p value (correlation } \\
\text { coefficient) }\end{array}$ \\
\hline Quality of life (total score) & $76.4(16.5)$ & $0.000 *(-0.253)$ \\
\hline General health status & $67.0(20.1)$ & $0.000 *(-0.345)$ \\
\hline \multicolumn{3}{|l|}{ Functional aspect } \\
\hline Physical function & 75.9 (22.9) & $0.015^{*}(-0.142)$ \\
\hline Role function & $73.8(29.8)$ & $0.071(-0,105)$ \\
\hline Emotional function & $80.5(20.9)$ & $0.000 *(-0.241)$ \\
\hline Cognitive function & $84.5(20.3)$ & $0.000 *(-0.273)$ \\
\hline Social function & $81.5(23.3)$ & $0.124(-0.090)$ \\
\hline \multicolumn{3}{|l|}{ Symptom } \\
\hline Fatigue & $35.7(26.2)$ & $0.008^{*}(0.155)$ \\
\hline Nausea/Vomiting & $16.4(25.6)$ & $0.006^{*}(0.160)$ \\
\hline Pain & $32.6(30.5)$ & $0.001^{*}(0.191)$ \\
\hline Dispnea & $8.1(19.5)$ & $0.167(0.081)$ \\
\hline Insomnia & $30.2(34.2)$ & $0.507(0.039)$ \\
\hline Poor appetite & $29.6(34.5)$ & $0.000 *(0.212)$ \\
\hline Constipation & $17.4(29.2)$ & $0.029 *(0.127)$ \\
\hline Diarrhea & $8.9(21.3)$ & $0.219(0.072)$ \\
\hline Financial problem & $39.0(36.4)$ & $0.001^{*}(0.197)$ \\
\hline
\end{tabular}

et al., 2004). Study regarding financial toxicity in Indonesia is very limited. A small survey conducted in Jakarta showed that cancer survivors suffered from financial toxicity, even those who had health insurance (Pangestu \& Karnadi, 2018).

In a 2014 study on unmet needs of advanced cancer patients in Indonesia, Effendy argued that it is no surprise that many cancer patients reported unmet financial-related need given the large portion (3/4) of Indonesian population who were under-insured (Effendy et al., 2014). However, since 2014, the Indonesian government set up the Indonesian national health insurance, which covers cancer therapies (Agustina et al., 2019). This scheme offers comprehensive benefits for cancer treatment, despite the exception on some drugs, (e.g., Bevacizumab and Cetuximab) (Ministry of Health Republic of Indonesia, 2019a). But, even in the Southeast Asian countries with an established universal health coverage such as in Malaysia, the patients are still heavily burdened with OOP costs (Tangcharoensathien et al., 2011). 
The magnitude of financial hardship for cancer survivors may extent from the medical and non-medical (e.g., transportation) OOP costs, indirect costs due to loss of income, and to debt and bankruptcy following cancer treatment (Altice et al., 2017). Most participants in our study were referral patients from different regions in Indonesia, hence, transportation could be onerous for them. In the Indonesian custom, the patients are always accompanied by the family caregivers, commonly the husbands for the gynecologic cancer patients. Therefore, the caregiver may need to leave their job while paying extra expenses during cancer treatment and follow-up (Anggraeni \& Ekowati, 2011; Kristanti et al., 2017). Nevertheless, it warrants further studies to examine the financial toxicity problem, its source and impacts among Indonesia gynecologic cancer survivors and their caregivers.

For the poor families, having cancer could be more financially disastrous (Kimman et al., 2015). This present study also found the relationships of low family income with higher level of unmet needs and poor quality of life (QoL), confirming the findings of many previous studies done in both LMIC and HIC (Chang et al., 2014; Kimman et al., 2017; A Molassiotis et al., 2017; Rahman et al., 2014; Sleight et al., 2018). Patients who are socioeconomically disadvantaged may face more barriers to accessing healthcare service for cancer treatment and follow-up care (DiMartino et al., 2017; Niksic et al., 2015). The non-direct medical costs, which are not covered by insurance, along with the complex and time-consuming referral system were identified as the primary barriers for the Indonesian cancer patients to seek healthcare service (Fles et al., 2017).

In addition, our study findings highlight the gynecologic cancer survivor population who needs more supportive care to achieve a better quality of life. Our findings confirm previous

\section{REFERENCES}

Aaronson, N. K., Ahmedzai, S., Bergman, B., Bullinger, M., Cull, A., Duez, N. J., ... Takeda, F. (1993). The European Organisation for Research and Treatment of Cancer QLQ-C30: A quality-oflife instrument for use in international clinical trials in oncology. Journal of the National Cancer Institute, 85, 365-376. https://doi. org/10.1093/jnci/85.5.365

Agustina, R., Dartanto, T., Sitompul, R., Susiloretni, K. A., Suparmi, Achadi, E. L., ... Khusun, H. (2019). Universal health coverage in Indonesia: concept, progress, and challenges. Lancet, 393(10166), 75-102. https://doi.org/10.1016/S0140-6736(18)31647-7

Altice, C. K., Banegas, M. P., Tucker-Seeley, R. D., \& Yabroff, K. R. (2017). Financial hardships experienced by cancer survivors: A systematic review. Journal of the National Cancer Institute, 109(2), 1-17. https://doi.org/10.1093/jnci/djw205

Anggraeni, M., \& Ekowati, W. (2011). Family role in the achievement of post radical mastectomy self integrity patients. International Journal of Public Health Research, 1, 163-168.

Armes, J., Crowe, M., Colbourne, L., Morgan, H., Murrells, T., Oakley, C., ... Richardson, A. (2009). Patients' supportive care needs beyond the end of cancer treatment: A prospective, longitudinal survey. Journal of Clinical Oncology, 27(36), 6172-6179. https://doi. org/10.1200/JCO.2009.22.5151

Bender, J. L., Wiljer, D., To, M. J., Bedard, P. L., Chung, P., Jewett, M. A. S., ... Gospodarowicz, M. (2012). Testicular cancer survivors' study findings that the survivors who are in the early stage of post-treatment cancer survivorship, those who have more advanced cancer stage, those who receive combination therapy, and those who are of a younger age are among women needing special consideration (Hodgkinson et al., 2007b; Kimman et al., 2017; Molassiotis et al., 2017; Urbaniec et al., 2011). Such consideration would include maintaining or protecting their fertility and reproductive function is an important concern among younger age women.

\section{LIMITATIONS}

The present study findings must be taken with caution. Despite being the first multicentre study on gynecologic cancer survivors' unmet needs in Indonesia, our convenient sampling and relatively small sample size limit the generalizability of the study. Our cross-sectional design and the mixing of new and long-term post-treatment cancer survivors also have caveats. Temporality is known to play a strong role in cancer survivorship (Broom et al., 2017). Thus, survivors' perceived needs and quality of life may change as they live through cancer trajectory (Kimman et al., 2017).

\section{CONCLUSION}

This study adds to the body of evidence that a higher level of unmet need is linked with poor health-related quality of life and provides perspective regarding survivors of gynaecologic cancer. This study findings should encourage the government to provide the socio-economic safety net for the people affected with cancer, including their family. Our findings are also beneficial for supporting the development of the survivorship care service, which is yet to be established in Indonesia.

supportive care needs and use of online support: A cross-sectional survey. Supportive Care in Cancer, 20(11), 2737-2746. https://doi. org/10.1007/s00520-012-1395-x

Bray, F., Jacques, F., Isabelle, S., Rebecca L., S., Lindsey A., T., Ahmedin, J., \& 1. (2018). Global Cancer Statistics 2018: GLOBOCAN Estimates of Incidence and Mortality Worldwide for 36 Cancers in 185 Countries. CA Cancer J Clin, 0, 1-31. https://doi. org/10.3322/caac. 21492

Broom, A., Kenny, K., \& Kirby, E. (2017). On waiting, hauntings and surviving: Chronicling life with cancer through solicited diaries. https://doi.org/10.1177/0038026117719216

Chang, O., Choi, E. K., Kim, I. R., Nam, S. J., Lee, J. E., Lee, S. K., ... Cho, J. (2014). Association between socioeconomic status and altered appearance distress, body image, and quality of life among breast cancer patients. Asian Pacific Journal of Cancer Prevention. https://doi.org/10.7314/APJCP.2014.15.20.8607

DiMartino, L. D., Birken, S. A., \& Mayer, D. K. (2017). The Relationship Between Cancer Survivors' Socioeconomic Status and Reports of Follow-up Care Discussions with Providers. Journal of Cancer Education: The Official Journal of the American Association for Cancer Education, 32(4), 749-755. https://doi.org/10.1007/ s13187-016-1024-3

Effendy, C., Vissers, K., Osse, B. H. P., Tejawinata, S., VernooijDassen, M., \& Engels, Y. (2014). Comparison of problems and 
unmet needs of patients with advanced cancer in a european country and an asian country. Pain Practice. https://doi.org/10.1111/ papr.12196

Fitch, M. I. (2014). Supportive care framework: Theoretical underpinnings. In M. I. Fitch (Ed.), Supportive care framework: A foundation for person-centred care. Ontario: CANO/ACIO.

Fles, R., Bos, A. C. R. K., Supriyati, Rachmawati, D., Waliyanti, E., Tan, I. B., ... Dewi, F. S. T. (2017). The role of Indonesian patients' health behaviors in delaying the diagnosis of nasopharyngeal carcinoma. BMC Public Health. https://doi.org/10.1186/s12889-017-4429-y

Hastert, T. A., Young, G. S., Pennell, M. L., Padamsee, T., Zafar, S. Y., DeGraffinreid, C., ... Paskett, E. D. (2018). Financial burden among older, long-term cancer survivors: Results from the LILAC study. Cancer Medicine, 7(9), 4261-4272. https://doi.org/10.1002/ cam4.1671

Hodgkinson, K, Butow, P., Hunt, G. E., Pendlebury, S., Hobbs, K. M., Lo, S. K., \& Wain, G. (2007a). The development and evaluation of a measure to assess cancer survivors' unmet supportive care needs: The CaSUN (Cancer Survivors' Unmet Needs measure). PsychoOncology, Vol. 16, pp. 796-804. https://doi.org/10.1002/pon.1137

Hodgkinson, K., Butow, P., Fuchs, A., Hunt, G. E., Stenlake, A., Hobbs, K. M., ... Wain, G. (2007b). Long-term survival from gynecologic cancer: Psychosocial outcomes, supportive care needs and positive outcomes. Gynecologic Oncology, 104(2), 381-389. https://doi.org/10.1016/j.ygyno.2006.08.036

Kimman, M., Jan, S., Yip, C., Thabrany, H., Peters, S., Bhoo-Pathy, N., ... Klinwimol, T. (2015). Catastrophic health expenditure and 12-month mortality associated with cancer in Southeast Asia: Results from a longitudinal study in eight countries. BMC Medicine.

Kimman, M. L., Jan, S., Peters, S. A. E., Yip, C. H., Ngelangel, C. A., Bhoo-Pathy, N., \& Woodward, M. (2017). Health-related quality of life and psychological distress among cancer survivors in Southeast Asia: results from a longitudinal study in eight low- and middle-income countries. BMC Medicine, 15(1), 10. https://doi. org/10.1186/s12916-016-0768-2

Knobf, M. T., Ferrucci, L. M., Cartmel, B., Jones, B. A., Stevens, D., Smith, M., ... Mowad, L. (2012). Needs assessment of cancer survivors in Connecticut. Journal of Cancer Survivorship, 6(1), 1-10. https://doi.org/10.1007/s11764-011-0198-2

Kristanti, M. S., Setiyarini, S., \& Effendy, C. (2017). Enhancing the quality of life for palliative care cancer patients in Indonesia through family caregivers: a pilot study of basic skills training. BMC Palliative Care, 16(1), 4. https://doi.org/10.1186/ s12904-016-0178-4

Ministry of Health Republic of Indonesia. (2015). Data and information on cancer situation (Data dan Informasi Kesehatan Situasi Penyakit Kanker). Buletin Kanker, 1(1), 1-5. https://doi. org/10.1007/s13398-014-0173-7.2

Ministry of Health Republic of Indonesia. Ministry of Health Decree number HK.01.07/MENKES/707/2018 concerning National Formularium. , (2019).

Ministry of Health Republic of Indonesia. (2019b). World Cancer Day 2019. Retrieved July 16, 2019, from http://www.depkes.go.id/ article/view/19020100003/hari-kanker-sedunia-2019.html

Molassiotis, A., Yates, P., Li, Q., So, W., Pongthavornkamol, K., Pittayapan, P., ... Si, S. Y. H. (2017). Mapping unmet supportive care needs, quality-of-life perceptions and current symptoms in cancer survivors across the Asia-Pacific region: Results from the International STEP Study. Annals of Oncology, 28(10), 2552-2558. https://doi.org/10.1093/annonc/mdx350
Molassiotis, A, Yates, P., Li, Q., So, W., Pongthavornkamol, K., Pittayapan, P., ... Collaborators $\uparrow$, on behalf of the S. S. (2017). Mapping unmet supportive care needs, quality-of-life perceptions and current symptoms in cancer survivors across the Asia-Pacific region: results from the International STEP Study. Annals of Oncology, 28, 2552-2558. https://doi.org/10.1093/femsec/fix097

Molassiotis, Alex, Yates, P., Li, Q., So, W. K. W., Pongthavornkamol, K., Pittayapan, P., ... Si, S. Y. H. (2017). Mapping unmet supportive care needs, quality-of-life perceptions and current symptoms in cancer survivors across the Asia-Pacific region: Results from the International STEP Study. Annals of Oncology, 28(10), 2552-2558. https://doi.org/10.1093/annonc/mdx350

National Cancer Institute. (2019). NCI Dictionary. Retrieved from https://www.cancer.gov/publications/dictionaries/cancer-terms/ def/gynecologic-cancer

Nekhlyudov, L., Ganz, P. A., Arora, N. K., \& Rowland, J. H. (2017). Going beyond being lost in transition: A decade of progress in cancer survivorship. Journal of Clinical Oncology, 35(18), 1978-1981. https://doi.org/10.1200/JCO.2016.72.1373

Niksic, M., Rachet, B., Warburton, F. G., Wardle, J., Ramirez, A. J., \& Forbes, L. J. L. (2015). Cancer symptom awareness and barriers to symptomatic presentation in England--are we clear on cancer? British Journal of Cancer, 113(3), 533-542. https://doi.org/10.1038/ bjc. 2015.164

Pangestu, S., \& Karnadi, E. B. (2018). Financial toxicity in Indonesian cancer patients \& survivors: How it affects risk attitude. Cogent Medicine, O0(00), 1-17. https://doi.org/10.1080/23312 05X.2018.1525887

Perwitasari, D. A., Atthobari, J., Dwiprahasto, I., Hakimi, M., Gelderblom, H., Putter, H., ... Kaptein, A. A. (2011). Translation and validation of EORTC QLQ-C30 into Indonesian version for cancer patients in Indonesia. Japanese Journal of Clinical Oncology, 41(4), 519-529. https://doi.org/10.1093/jjco/hyq243

Putri, R. H., Afiyanti, Y., Ungsianik, T., \& Milanti, A. (2017). Supportive care needs and quality of life of patients with gynecological cancer undergoing therapy. Enfermería Clínica, 27(Suppl. Part I), 222-226. https:/doi.org/doi: 10.1016/S1130-8621(18)30072-X.

Rahman, M. M., Ahsan, M. A., Monalisa, N. N., \& Rahman, K. (2014). Influence of socioeconomic status and BMI on the quality of life after mastectomy in Bangladeshi breast cancer patients in a public hospital. Japanese Journal of Clinical Oncology, 44(12), 1150-1157. https://doi.org/10.1093/jico/hyu144

Ratain, M. J. (2009). Biomarkers and clinical care. AAAS/FDLI Colloquium, Personalized Medicine in an Era of Health Care Reform, Washington, $D C$.

Rosenberg, S. M., \& Partridge, A. H. (2017). Looking back, moving forward: the evolution of cancer survivorship care. The Lancet Oncology, 18(1), 18-19. https://doi.org/10.1016/ S1470-2045(16)30649-0

Salani, R., Khanna, N., Frimer, M., Bristow, R. E., \& Chen, L. may. (2017). An update on post-treatment surveillance and diagnosis of recurrence in women with gynecologic malignancies: Society of Gynecologic Oncology (SGO) recommendations. Gynecologic Oncology, 146(1), 3-10. https://doi.org/10.1016/j.ygyno.2017.03.022

Schlumbrecht, M., Sun, C., Huang, M., Milbourne, A., \& Bodurka, D. (2018). Gynecologic cancer survivor preferences for long-term surveillance. BMC Cancer, 18(1), 1-10. https://doi.org/10.1186/ s12885-018-4313-x

Schmeler, K. M., Jhingran, A., Iyer, R. B., Sun, C. C., Eifel, P. J., Soliman, P. T., ... Sood, A. K. (2010). Pelvic fractures after radiotherapy for cervical cancer. Cancer, 116(3), 625-630. https:// doi.org/10.1002/cncr.24811 
Shih, K. K., Folkert, M. R., Kollmeier, M. A., Abu-Rustum, N. R., Sonoda, Y., Leitao, M. M., ... Alektiar, K. M. (2013). Pelvic insufficiency fractures in patients with cervical and endometrial cancer treated with postoperative pelvic radiation. Gynecologic Oncology, 128(3), 540-543. https://doi.org/10.1016/j. ygyno.2012.12.021

Sleight, A. G., Lyons, K. D., Vigen, C., Macdonald, H., \& Clark, F. (2018). The association of health-related quality of life with unmet supportive care needs and sociodemographic factors in lowincome Latina breast cancer survivors: a single-centre pilot study. Disability and Rehabilitation, 0(0), 1-6. https://doi.org/10.1080/0963 8288.2018.1485179

Smith, A., King, M., Butow, P., Luckett, T., Grimison, P., Toner, G., ... Olver, I. (2013). The prevalence and correlates of supportive care needs in testicular cancer survivors: a cross-sectional study. Psychooncology, 22(11), 2557-2564. https://doi.org/10.1002/ pon. 3323

So, W. K. W., Chan, C. W. H., Choi, K. C., Wan, R. W. M., Mak, S. S. S., \& Chair, S. Y. (2013). Perceived unmet needs and health-related quality of life of Chinese cancer survivors at 1 year after treatment. Cancer Nursing, Vol. 36, pp. E23-E32. https://doi.org/DOI: 10.1097/ NCC.0b013e318263f28e Perceived
So, W. K. W., Ming, K. M., Chan, H. Y. L., Chow, K. C., Wan, R. W. M., Mak, S. S. S., ... Chan, C. W. H. (2014). Quality of life and most prevalent unmet needs of Chinese breast cancer survivors at one year after cancer treatment. European Journal of Oncology Nursing, 18(3), 323-328. https://doi.org/10.1016/j.ejon.2014.03.002

Tangcharoensathien, V., Patcharanarumol, W., Ir, P., Aljunid, S., Mukti, A., \& Akkhavong, K, et al. (2011). Health-financing reforms in southeast Asia: challenges in achieving universal coverage. The Lancet, 377, 863-73.

Urbaniec, O. A., Collins, K., Denson, L. A., \& Whitford, H. S. (2011). Gynecological cancer survivors: Assessment of psychological distress and unmet supportive care needs. Journal of Psychosocial Oncology, Vol. 29, pp. 534-551. https://doi.org/DOI: 10.1080/07347332.2011.599829

Yabroff, K. R., Lawrence, W. F., Clauser, S., Davis, W. W., \& Brown, M. L. (2004). Burden of illness in cancer survivors: findings from a population-based national sample. Journal of the National Cancer Institute, 96(17), 1322-1330. https://doi.org/10.1093/jnci/djh255 